\title{
Pituitary Apoplexy Associated with Endocrine Stimulation Test: Endocrine Stimulation Test, Treatment, and Outcome
}

\author{
Takahiro Yamamoto, Shigetoshi Yano, Jun-ichiro Kuroda, Yu Hasegawa, \\ Takuichiro Hide, and Jun-ichi Kuratsu
}

Department of Neurosurgery, Faculty of Life Sciences, Kumamoto University School of Medicine, 1-1-1, Honjo, Kumamoto 861-8556, Japan

Correspondence should be addressed to Shigetoshi Yano, yanos@kumamoto-u.ac.jp

Received 11 March 2012; Accepted 14 May 2012

Academic Editors: C. Capella, W. V. Moore, and S. Simsek

Copyright ( $) 2012$ Takahiro Yamamoto et al. This is an open access article distributed under the Creative Commons Attribution License, which permits unrestricted use, distribution, and reproduction in any medium, provided the original work is properly cited.

\begin{abstract}
Pituitary apoplexy is a rare clinical syndrome attributable to hemorrhage or hemorrhagic infarction of pituitary tumors or pituitary glands. The features of pituitary apoplexy associated with the endocrine stimulation test remain to be elucidated and the importance of surgical treatment has not been discussed enough. We report two rare patients who were treated successfully by endoscopic endonasal transsphenoidal surgery within several hours after onset of pituitary apoplexy associated with the endocrine stimulation test. Their postoperative course was uneventful. We reviewed earlier reports on this clinical entity, document its features especially as related to the endocrine stimulation test, discuss the significance of immediate surgical treatment, and present our treatment outcomes. Performing only conservative treatment is not recommended. We suggest that the necessity of endocrine stimulation test should be assessed on a case-by-case basis and in patients subjected to the test, and neurosurgical support should be sought.
\end{abstract}

\section{Introduction}

Pituitary apoplexy is a life-threatening clinical syndrome thought to be attributable to hemorrhage or hemorrhagic infarction of pituitary tumors or pituitary glands [1]. Suggested precipitating factors are hypertension, anticoagulation, and bromocriptine therapy, and pregnancy [2-27]. There are few reports on the occurrence of pituitary apoplexy as a complication of the endocrine stimulation test, and its features remain to be elucidated. We report two rare patients with pituitary apoplexy associated with the endocrine stimulation test who were treated successfully by surgery and present a review of the literature. We also discussed about the necessity of neurosurgical support.

\section{Case Presentation}

2.1. Case 1. A 56-year-old woman with a one-year history of visual disturbance was admitted to our hospital for the evaluation of a suprasellar tumor. Physical examination at admission revealed visual disturbance (temporal hemianopia on the left side) but no other neurological disorders or endocrinological symptoms. Her baseline levels of pituitary hormones were normal. Computed tomography (CT) and magnetic resonance imaging (MRI) studies demonstrated a pituitary adenoma with suprasellar extension and superior displacement of the optic chiasm. To evaluate her hormonal responses we performed combined endocrine stimulation tests with growth-hormone-releasing hormone $(\mathrm{GRH}$, $100 \mu \mathrm{g}$ ), thyrotropin-releasing hormone (TRH, 250 $\mu \mathrm{g}$ ), luteinizing hormone-releasing hormone (LH-RH, $100 \mu \mathrm{g}$ ), and corticotrophin-releasing hormone (CRH, $100 \mu \mathrm{g})$. Fifteen minutes after the intravenous bolus injection she complained of severe headache, and this was followed by vomiting, progressive visual disturbance, and left oculomotor paralysis. She was alert but her symptoms gradually worsened. Emergency CT and MRI revealed intratumoral hemorrhage (Figures 1(a)-1(d)). Four hours after onset, her 


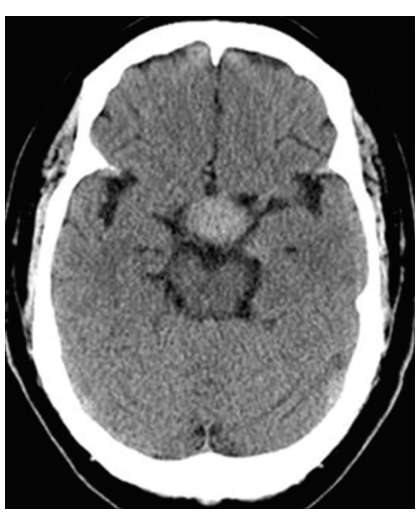

(a)

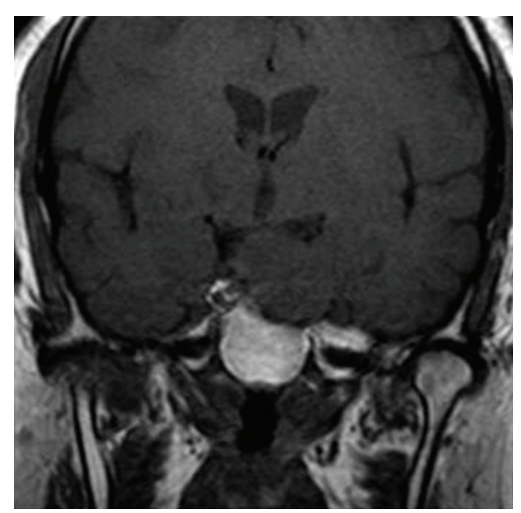

(b)

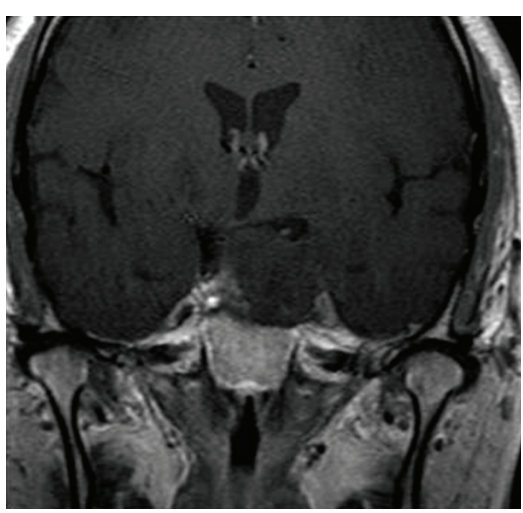

(c)

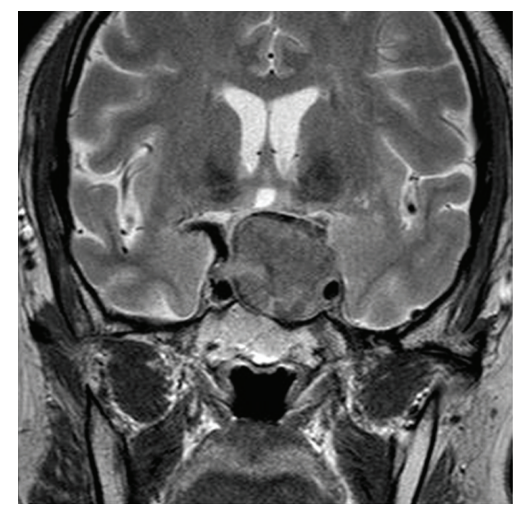

(d)

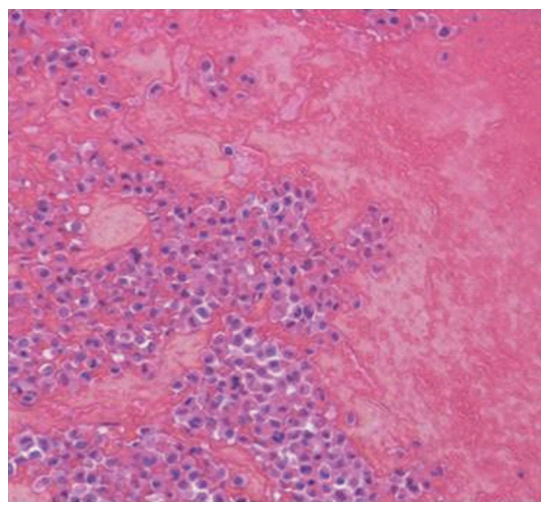

(e)

FIguRE 1: Case 1. CT scan performed $1 \mathrm{hr}$ after onset demonstrates intratumoral hemorrhage (a), T1-weighted MRI showing a pituitary tumor extending into the suprasellar cistern (b), after onset gadolinium enhanced coronal T1-weighted MRI showing no enhancement of the pituitary tumor (c), T2-weighted MRI showing a pituitary tumor with a low-signal-intensity rim. This finding was suggestive of pituitary apoplexy (d), Specimen stained with hematoxylin and eosin. Hemorrhage and necrosis on the right side of the picture and area of nonnecrotic papillary-patterned tumor tissue on the left (e).

left visual acuity was reduced to total blindness; there was temporal hemianopia in the right visual field. At emergency endoscopic endonasal transsphenoidal surgery was (ETSS) performed $5 \mathrm{hr}$ after onset. Partially, tumor was solid and reddish-brown, different from the typical feature of pituitary adenoma. The tumor was totally removed. Pathological examination revealed hemorrhagic and necrotic area in nonnecrotic papillary-patterned tumor tissue (Figure 1(e)). Postoperatively, her headache, nausea and left oculomotor paralysis resolved, and her vision returned to the preonset level. Because of her diabetes insipidus (DI) she received transient desmopressin replacement therapy. She was able to resume her normal life.

2.2. Case 2. A 73-year-old man with an 8-month history of visual disturbance was referred to our hospital. Five years earlier, when he was diagnosed with suprasellar tumor, he was asymptomatic and without visual disturbance. In the intervening five years, his tumor gradually enlarged and became symptomatic. At admission to our hospital, visual field examination revealed temporal hemianopia on the left side.
He had no other neurological disorders or endocrinological symptoms. His baseline pituitary hormone levels were normal. CT and MRI demonstrated a pituitary adenoma with suprasellar extension and superior displacement of the optic chiasm. For preoperative endocrine evaluation we performed combined endocrine stimulation tests with growth hormone releasing peptide-2 (GHRP2, $100 \mu \mathrm{g})$, TRH $(250 \mu \mathrm{g}), \mathrm{LH}-$ RH $(100 \mu \mathrm{g})$, and CRH $(100 \mu \mathrm{g})$. Twenty minutes after the intravenous bolus injection he complained of progressive visual disturbance. He was alert and experienced neither headache nor nausea. Emergency CT and MRI performed one hr after onset showed no evidence of intratumoral hemorrhage (Figures 2(a)-2(c)), two hr after onset his left visual acuity was reduced to total blindness. There was no visual disturbance on the right side. He underwent ETSS $5 \mathrm{hr}$ after onset, and the tumor was totally removed. Same as Case 1, tumor was partially solid and reddish-brown. Pathological examination revealed papillary-patterned adenoma with diffuse hemorrhage and necrosis (Figure 2(d)). His postoperative course was uneventful. One month after the operation his visual disturbance resolved completely, and he required no hormone replacement therapy. 


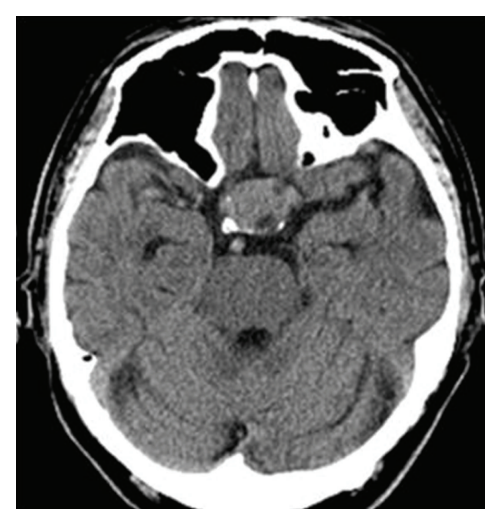

(a)

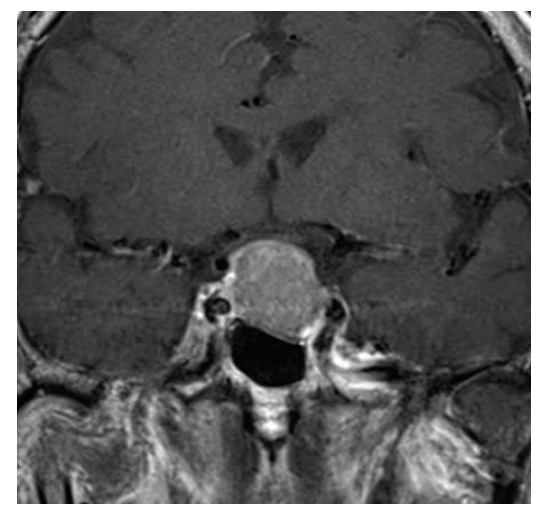

(c)

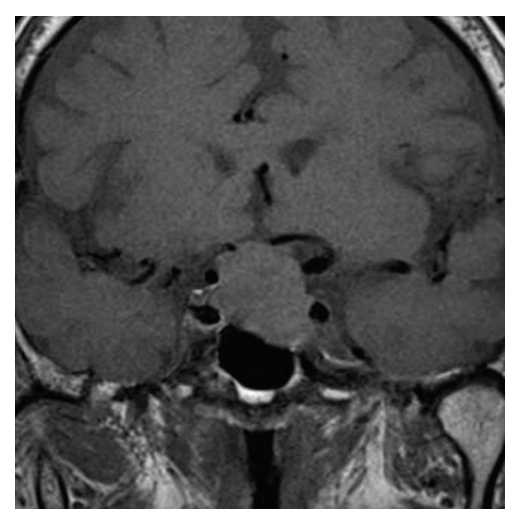

(b)

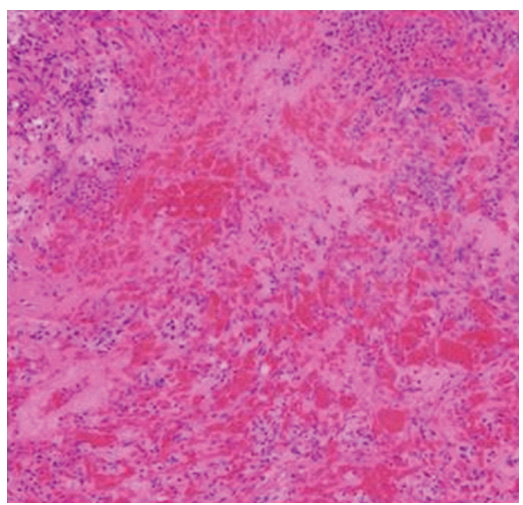

(d)

Figure 2: Case 2. CT scan performed 1 hour after onset demonstrates no evidence of intratumoral hemorrhage or acute enlargement of the tumor size (a), T1-weighted MRI performed after onset shows a pituitary tumor extending into the suprasellar cistern. There was no evidence of intratumoral hemorrhage or acute infarction (b), after onset gadolinium-enhanced T1-weighted MRI showing uniform enhancement of the pituitary tumor (c), and pathological examination revealed papillary-patterned adenoma with diffuse hemorrhage and necrosis (d).

\section{Discussion}

Pituitary apoplexy is a rare clinical syndrome thought to be attributable to hemorrhage or hemorrhagic infarction of pituitary tumors or pituitary glands. It is characterized by the sudden onset of headache, vomiting, visual impairment, and decreased consciousness. Reported precipitating factors of pituitary apoplexy are hypertension, anticoagulation and bromocriptine therapy, pregnancy, and angiography [1, 22]. Although pituitary apoplexy associated with the endocrine stimulation test has been reported (Table 1), its features remain to be elucidated [2-27]. Of the 32 previouslyreported patients and our two patients with pituitary adenomas who experienced pituitary apoplexy, 16 (47\%) had nonfunctioning, 8 (23.5\%) GH-secreting, 5 (14.7\%) prolactin (PRL)-secreting, $3(8.8 \%)$ follicle-stimulating hormone (FSH)-secreting, and 2 (5.9\%) had adrenocorticotropic hormone (ACTH)-secreting adenomas. This proportion is similar to the frequency among the types of pituitary adenomas [28]. This suggests that there is no strong correlation between the types of pituitary adenoma and the elicitation of pituitary apoplexy by the endocrine stimulation test. On the other hand, there appears to be a relationship between the size of pituitary adenomas and pituitary apoplexy associated with the endocrine stimulation test. Our review of the literature showed that $93 \%$ of previouslyn reported patients manifested extrasellar extension of their pituitary tumors. TRH (26 cases, 76.4\%) and LH-RH (23 cases, 67.6\%) were the hormonal stimulants most commonly associated with the elicitation of pituitary apoplexy. Although the precise mechanisms of pituitary apoplexy associated with TRH- and LH-RH stimulation remain unclear, it has been suggested that TRH elevates the serum level of norepinephrine, and that vasospasm or pressor effects may be precipitating factors $[3,15,29]$. Others proposed that TRH directly activates the tumor cells, or that LH-RH stimulation increases metabolic activity leading to vascular accidents $[6,12,15,18,29]$. Interestingly, the number of hormonal stimulants used in the endocrine stimulation test has no bearing on the elicitation of pituitary apoplexy; the Spearman correlation was $\rho=$ -0.40 with a $P$ value of 0.6 (Table $1(\mathrm{a})$ ). Excluding the two patients reported here, the incidence of pituitary apoplexy among patients subjected to the endocrine stimulation test with four stimulants was 0 in our department. Because this 
TABle 1

(a) Reported cases of pituitary apoplexy associated with endocrine stimulation test: diagnosis, extension, and stimulation test

\begin{tabular}{|c|c|c|c|c|c|c|}
\hline Case no. & Author & Year & Age/sex & Diagnosis & Extension & Stimulation test \\
\hline 1 & Dunn et al. & 1975 & $22 / \mathrm{F}$ & GH secreting & Uncertain & TRH, glucose, insulin \\
\hline 2 & Silverman et al. & 1978 & $31 / \mathrm{M}$ & PRL secreting & Extrasellar extension & Chlorpromazine \\
\hline 3 & Jordan et al. & 1979 & $21 / \mathrm{F}$ & ACTH secreting & Uncertain & Dexamethasone \\
\hline 4 & Cimino et al. & 1981 & $48 / \mathrm{M}$ & Nonfunctioning & Extrasellar extension & TRH, LH-RH \\
\hline 5 & Drury et al. & 1982 & $59 / \mathrm{F}$ & Nonfunctioning & Extrasellar extension & TRH, LH-RH, glucagon \\
\hline 6 & Drury et al. & 1982 & $66 / \mathrm{M}$ & GH secreting & Intrasellar & $\mathrm{TRH}$ \\
\hline 7 & Drury et al. & 1982 & $39 / \mathrm{F}$ & PRL secreting & Extrasellar extension & TRH, LH-RH \\
\hline 8 & Drury et al. & 1982 & $28 / \mathrm{M}$ & PRL secreting & Extrasellar extension & TRH, LH-RH \\
\hline 9 & Bernstein et al. & 1984 & $48 / \mathrm{M}$ & Nonfunctioning & Extrasellar extension & TRH, LH-RH, insulin \\
\hline 10 & Korsic & 1994 & $56 / \mathrm{M}$ & FSH secreting & Extrasellar extension & LH-RH \\
\hline 11 & Chapman et al. & 1979 & $39 / \mathrm{F}$ & PRL secreting & Extrasellar extension & TRH, LH-RH, insulin \\
\hline 12 & Lever et al. & 1986 & $19 / \mathrm{F}$ & GH secreting & Intrasellar & $\mathrm{TRH}$ \\
\hline 13 & Shirataki et al. & 1988 & $50 / \mathrm{F}$ & GH secreting & Extrasellar extension & Bromocriptine \\
\hline 14 & Harvey et al. & 1989 & $50 / \mathrm{M}$ & Nonfunctioning & Uncertain & Insulin \\
\hline 15 & Arafah et al. & 1990 & $41 / \mathrm{F}$ & PRL secreting & Extrasellar extension & LH-RH \\
\hline 16 & Masson et al. & 1993 & $54 / \mathrm{F}$ & FSH secreting & Extrasellar extension & LH-RH \\
\hline 17 & Okuda et al. & 1994 & $60 / \mathrm{F}$ & Nonfunctioning & Extrasellar extension & TRH, LH-RH, insulin \\
\hline 18 & Vassallo et al. & 1994 & $81 / \mathrm{M}$ & Nonfunctioning & Uncertain & TRH, LH-RH, L-Dopa \\
\hline 19 & Masago et al. & 1995 & $48 / \mathrm{M}$ & FSH secreting & Extrasellar extension & TRH, LH-RH, insulin \\
\hline 20 & Masago et al. & 1995 & $54 / \mathrm{M}$ & Nonfunctioning & Extrasellar extension & TRH, LH-RH \\
\hline 21 & Szabolcs et al. & 1997 & $54 / \mathrm{M}$ & Nonfunctioning & Extrasellar extension & TRH \\
\hline 22 & Otsuka et al. & 1998 & $31 / \mathrm{F}$ & GH secreting & Extrasellar extension & GRF, TRH, LH-RH, CRH \\
\hline 23 & Dökmetaş et al. & 1999 & $28 / \mathrm{F}$ & GH secreting & Extrasellar extension & $\mathrm{TRH}$ \\
\hline 24 & Sanno et al. & 1999 & $55 / \mathrm{M}$ & Nonfunctioning & Extrasellar extension & GRF, TRH, LH-RH, CRH \\
\hline 25 & Lee et al. & 2000 & $34 / \mathrm{M}$ & GH secreting & Extrasellar extension & TRH, LH-RH, insulin \\
\hline 26 & Riedl et al. & 2000 & $71 / \mathrm{F}$ & Nonfunctioning & Extrasellar extension & GRF, TRH, LH-RH, CRH \\
\hline 27 & Matsuura et al. & 2001 & $63 / \mathrm{M}$ & Nonfunctioning & Extrasellar extension & TRH, LH-RH, insulin \\
\hline 28 & Rotman et al. & 2003 & $19 / \mathrm{F}$ & ACTH secreting & Extrasellar extension & $\mathrm{CRH}$ \\
\hline 29 & Yoshino et al. & 2007 & $36 / \mathrm{M}$ & Nonfunctioning & Extrasellar extension & TRH, LH-RH, insulin \\
\hline 30 & Yoshino et al. & 2007 & $38 / \mathrm{M}$ & Nonfunctioning & Extrasellar extension & TRH, insulin \\
\hline 31 & Wang et al. & 2007 & $41 / \mathrm{F}$ & GH secreting & Extrasellar extension & TRH, LH-RH, insulin, L-Dopa \\
\hline 32 & Kilıçlı et al. & 2010 & $52 / \mathrm{M}$ & Nonfunctioning & Extrasellar extension & TRH, LH-RH, insulin \\
\hline 33 & Our cases & 2011 & $56 / \mathrm{F}$ & Nonfunctioning & Extrasellar extension & GRF, TRH, LH-RH, CRH \\
\hline 34 & Our cases & 2011 & $73 / \mathrm{M}$ & Nonfunctioning & Extrasellar extension & GHRP2, TRH, LH-RH, CRH \\
\hline
\end{tabular}

(b) Reported cases of pituitary apoplexy associated with endocrine stimulation test: treatment and outcomes of the 23 cases, for whom detailed treatments and outcomes were available

\begin{tabular}{llll}
\hline $\begin{array}{l}\text { Case } \\
\text { no. }\end{array}$ & Treatment & Interval from onset to surgery & Outcomes \\
\hline 1 & Medication & - & GH reduction, DI \\
2 & Craniotomy & Undocumented & Panhypopituitarism \\
3 & Craniotomy & Undocumented & Visual disturbance, hemiparesis, aphasia \\
9 & Transsphenoidal surgery & The same day (8.5 hours $)$ & Visual disturbance, hemiparesis, aphasia \\
11 & Craniotomy & 3 days later & Recovered completely \\
13 & Transsphenoidal surgery & 11 days later & Recovered completely \\
14 & Transsphenoidal surgery & Undocumented & Hypopituitarism \\
17 & Craniotomy & The same day and 17 days after & Recovered completely \\
18 & Medication & - & Hypopituitarism \\
19 & Craniotomy & The same day (7 hours $)$ & Recovered completely \\
\hline
\end{tabular}


(b) Continued.

\begin{tabular}{llll}
\hline $\begin{array}{l}\text { Case } \\
\text { no. }\end{array}$ & Treatment & Interval from onset to surgery & Outcomes \\
\hline 20 & Craniotomy & 5 days later & Hypopituitarism \\
22 & Transsphenoidal surgery & 4 days later & Hypopituitarism \\
24 & Transsphenoidal surgery & 2 weeks later & Hypopituitarism \\
25 & Transsphenoidal surgery & 9 days later & Hypopituitarism \\
26 & Transsphenoidal surgery & 2 days later & Visual disturbance, ophthalmoplegia \\
27 & Transsphenoidal surgery & 1 day later (30 hours) & Improved to the level of preoperative state \\
28 & Medication & - & Hypopituitarism \\
29 & Transsphenoidal surgery & The same day and 21 days after & Hypopituitarism \\
30 & Transsphenoidal surgery & 7 days later & Hypopituitarism \\
31 & Transsphenoidal surgery & 2 days later & Ophthalmoplegia \\
32 & Transsphenoidal surgery & The same day & Recovered completely \\
33 & Transsphenoidal surgery & The same day & Visual disturbance \\
34 & Transsphenoidal surgery & The same day & Recovered completely \\
\hline
\end{tabular}

test is convenient and the incidence of test-elicited pituitary apoplexy is low, it is used widely to investigate the reserve function of the pituitary in patients with pituitary adenoma. Nonetheless, based on earlier reports and our experience with the two patients reported here, we think that the necessity for performing the endocrine stimulation test must be evaluated on a case-by-case basis.

Among the 34 patients, detailed treatments and outcomes were available in 23 (Table 1(b)); 20 patients underwent surgery, and the other 3 were treated conservatively $[3,4,7,8,11,13-15,17-23,26,27,29]$. Of the latter, all experienced symptom exacerbation after suffering pituitary apoplexy $[7,8,14,21,26]$. Among the 20 surgically treated patients, in 14 the symptoms worsened after the occurrence of pituitary apoplexy while in the other six they were unchanged or improved $[3,4,11,13,15,17-20,22,23$, $27,29]$. In three patients who underwent tumor removal on the day of onset of pituitary apoplexy, the symptoms were worse after than before onset while in another four they were improved or unchanged $[3,11,15,18,29]$. In our cases, the patients underwent surgery within $5 \mathrm{hr}$ of apoplexy onset, the symptoms attributable to pituitary apoplexy were improved. Because pituitary apoplexy associated with the above-cited precipitating factors is rare, controversy continues to surround the standard treatment [1]. In some instances the symptoms associated with precipitating factors improved when surgery was performed within 7-8 days of apoplexy onset $[1,30]$.

Our review of the literature suggests that patients with pituitary apoplexy elicited by the endocrine stimulation test should be operated within several hours after its onset, that is, sooner than patients with pituitary apoplexy associated with the other precipitating factors. Performing only conservative treatment is not recommended. We recommend that the necessity for endocrine stimulation tests should be considered carefully and that they be performed with neurosurgical support.

\section{References}

[1] S. Rajasekaran, M. Vanderpump, S. Baldeweg et al., "UK guidelines for the management of pituitary apoplexy," Clinical Endocrinology, vol. 74, no. 1, pp. 9-20, 2011.

[2] B. M. Arafah, J. F. Harrington, Z. T. Madhoun, and W. R. Selman, "Improvement of pituitary function after surgical decompression for pituitary tumor apoplexy," Journal of Clinical Endocrinology and Metabolism, vol. 71, no. 2, pp. 323-328, 1990.

[3] M. Bernstein, R. A. Hegele, F. Gentili et al., "Pituitary apoplexy associated with a triple bolus test. Case report," Journal of Neurosurgery, vol. 61, no. 3, pp. 586-590, 1984.

[4] A. J. Chapman, G. Williams, A. D. Hockley, and D. R. London, "Pituitary apoplexy after combined test of anterior pituitary function," British Medical Journal, vol. 291, no. 6487, p. 26, 1985.

[5] A. Cimino, R. Corsini, E. Radaeli, A. Bollati, and G. Giustina, "Transient amaurosis in patient with pituitary macroadenoma after intravenous gonadotropin and thyrotropin releasing hormones," The Lancet, vol. 2, no. 8237, p. 95, 1981.

[6] H. S. Dökmetaş, A. Selçuklu, R. Çolak, K. Ünlühizarci, F. Bayram, and F. Keleştimur, "Pituitary apoplexy probably due to TRH and GnRH stimulation tests in a patient with acromegaly," Journal of Endocrinological Investigation, vol. 22, no. 9, pp. 698-700, 1999.

[7] P. L. Drury, P. E. Belchetz, W. I. McDonald, D. G. Thomas, and G. M. Besser, "Transient amaurosis and headache after thyrotropin releasing hormone," The Lancet, vol. 1, no. 8265, pp. 218-219, 1982.

[8] P. J. Dunn, R. A. Donald, and E. A. Espiner, "Regression of acromegaly following pituitary apoplexy," Australian and New Zealand Journal of Medicine, vol. 5, no. 4, pp. 369-372, 1975.

[9] R. Harvey, M. Michelagnoli, P. McHenry, D. G. Currie, and P. D. Bewsher, "Pituitary apoplexy," British Medical Journal, vol. 298, no. 6668, p. 258, 1989.

[10] R. M. Jordan, D. M. Cook, J. W. Kendall, and C. W. Kerber, "Nelson's syndrome and spontaneous pituitary tumor infarction," Archives of Internal Medicine, vol. 139, no. 3, pp. 340342, 1979. 
[11] F. Kiliçli, H. S. Dökmetaş, and M. Gürelik, "Development of pituitary apoplexy during TRH/GnRH test in a patient with pituitary macroadenoma," Singapore Medical Journal, vol. 51, no. 11, pp. e179-e181, 2010.

[12] M. Korsic, "Pituitary apoplexy following the administration of gonadotrophin releasing hormone," Clinical Endocrinology, vol. 41, no. 5, pp. 696-697, 1994.

[13] D. H. Lee, M. Y. Chung, D. J. Chung et al., "Apoplexy of pituitary macroadenoma after combined test of anterior pituitary function," Endocrine Journal, vol. 47, no. 3, pp. 329-333, 2000.

[14] E. G. Lever, J. Butler, and P. Moore, "Infarction of a growth hormone-secreting macroadenoma during a TRH test," Acta Endocrinologica, vol. 112, no. 2, pp. 172-179, 1986.

[15] A. Masago, Y. Ueda, H. Kanai et al., "Pituitary apoplexy after pituitary function test: a report of two cases and review of the literature," Surgical Neurology, vol. 43, no. 2, pp. 158-165, 1995.

[16] E. A. Masson, S. L. Atkin, M. Diver, and M. C. White, "pituitar$\mathrm{y}$ apoplexy and sudden blindness following the administration of gonadotrophin releasing hormone," Clinical Endocrinology, vol. 38, no. 1, pp. 109-110, 1993.

[17] I. Matsuura, N. Saeki, M. Kubota, H. Murai, and A. Yamaura, "Infarction followed by hemorrhage in pituitary adenoma due to endocrine stimulation test," Endocrine Journal, vol. 48, no. 4, pp. 493-498, 2001.

[18] O. Okuda, H. Umezawa, and M. Miyaoka, "Pituitary apoplexy caused by endocrine stimulation tests: a case report," Surgical Neurology, vol. 42, no. 1, pp. 19-22, 1994.

[19] F. Otsuka, J. Kageyama, T. Ogura, and H. Makino, "Pituitary apoplexy induced by a combined anterior pituitary test: case report and literature review," Endocrine Journal, vol. 45, no. 3, pp. 393-398, 1998.

[20] M. Riedl, M. Clodi, H. Kotzmann et al., "Apoplexy of a pituitary macroadenoma with reversible third, fourth and sixth cranial nerve palsies following administration of hypothalamic releasing hormones: MR features," European Journal of Radiology, vol. 36, no. 1, pp. 1-4, 2000.

[21] P. Rotman-Pikielny, N. Patronas, and D. A. Papanicolaou, "Pituitary apoplexy induced by corticotrophin-releasing hormone in a patient with Cushing's disease," Clinical Endocrinology, vol. 58, no. 5, pp. 545-549, 2003.

[22] N. Sanno, Y. Ishii, M. Sugiyama, R. Takagi, Y. Node, and A. Teramoto, "Subarachnoid haemorrhage and vasospasm due to pituitary apoplexy after pituitary function tests," Acta Neurochirurgica, vol. 141, no. 9, pp. 1009-1010, 1999.

[23] K. Shirataki, K. Chihara, Y. Shibata, N. Tamaki, S. Matsumoto, and T. Fujita, "Pituitary apoplexy manifested during a bromocriptine test in a patient with a growth hormone- and prolactin-producing pituitary adenoma," Neurosurgery, vol. 23, no. 3, pp. 395-398, 1988.

[24] V. E. Silverman, A. E. Boyd, J. A. McCrary III, and P. O. Kohler, "Pituitary apoplexy following chlorpromazine stimulation," Archives of Internal Medicine, vol. 138, no. 11, pp. 1738-1739, 1978.

[25] I. Szabolcs, N. Késmárki, K. Bor et al., “Apoplexy of a pituitary macroadenoma as a severe complication of preoperative thyrotropin-releasing hormone (TRH) testing," Experimental and Clinical Endocrinology and Diabetes, vol. 105, no. 4, pp. 234236, 1997.

[26] M. Vassallo, Z. Rana, and S. Allen, "Pituitary apoplexy after stimulation tests," Postgraduate Medical Journal, vol. 70, no. 824, pp. 444-445, 1994.

[27] H. F. Wang, C. C. Huang, Y. F. Chen, D. M. T. Ho, and H. D. Lin, "Pituitary apoplexy after thyrotropin-releasing hormone stimulation test in a patient with pituitay macroadenoma," Journal of the Chinese Medical Association, vol. 70, no. 9, pp. 392-395, 2007.

[28] G. Mohr and J. Hardy, "Hemorrhage, necrosis, and apoplexy in pituitary adenomas," Surgical Neurology, vol. 18, no. 3, pp. 181-189, 1982.

[29] A. Yoshino, Y. Katayama, T. Watanabe et al., "Apoplexy accompanying pituitary adenoma as a complication of preoperative anterior pituitary function tests," Acta Neurochirurgica, vol. 149, no. 6, pp. 557-565, 2007.

[30] Y. Hasegawa, S. Yano, T. Sakurama et al., "Endoscopic surgical treatment for pituitary apoplexy in three elderly patients over the age of 80," Acta Neurochirurgica Supplementum, vol. 111, part 6, pp. 429-433, 2011. 


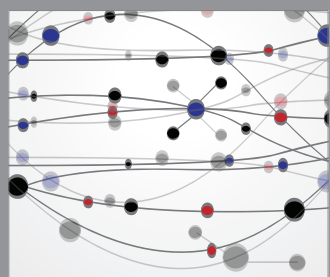

The Scientific World Journal
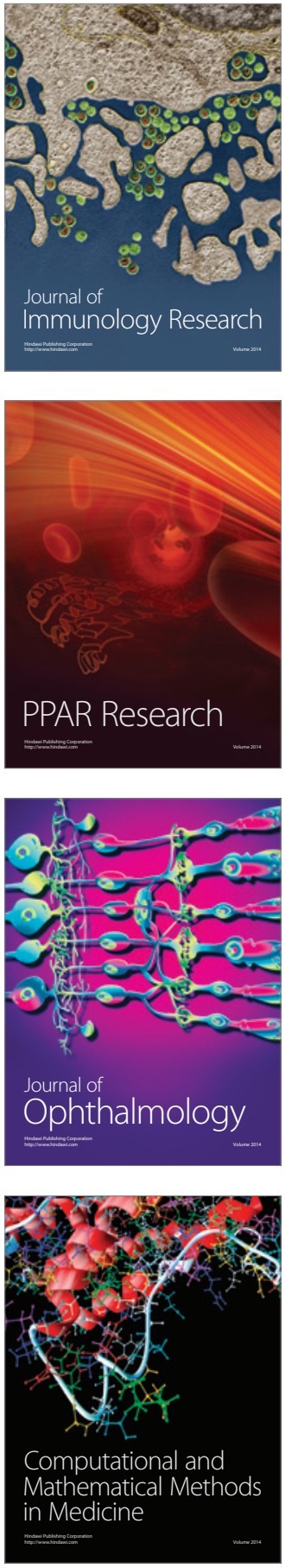

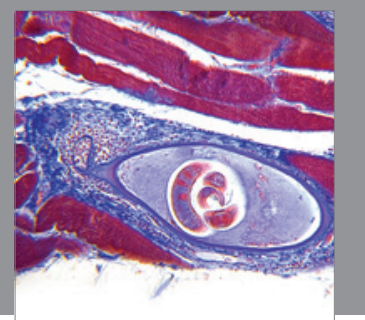

Gastroenterology

Research and Practice
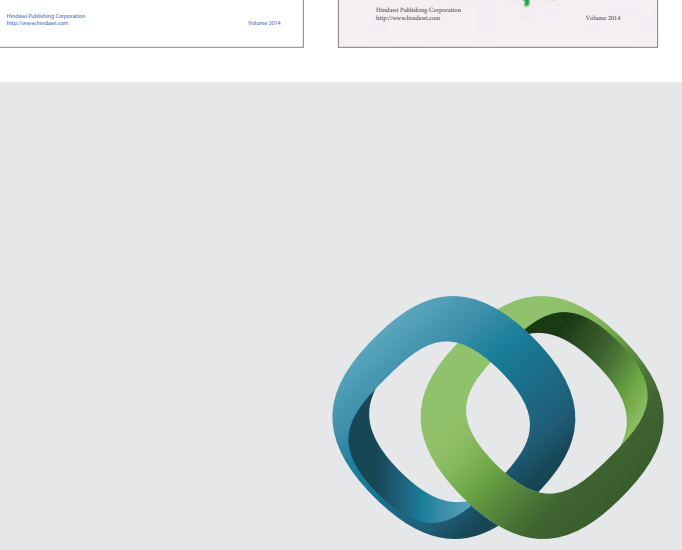

\section{Hindawi}

Submit your manuscripts at

http://www.hindawi.com
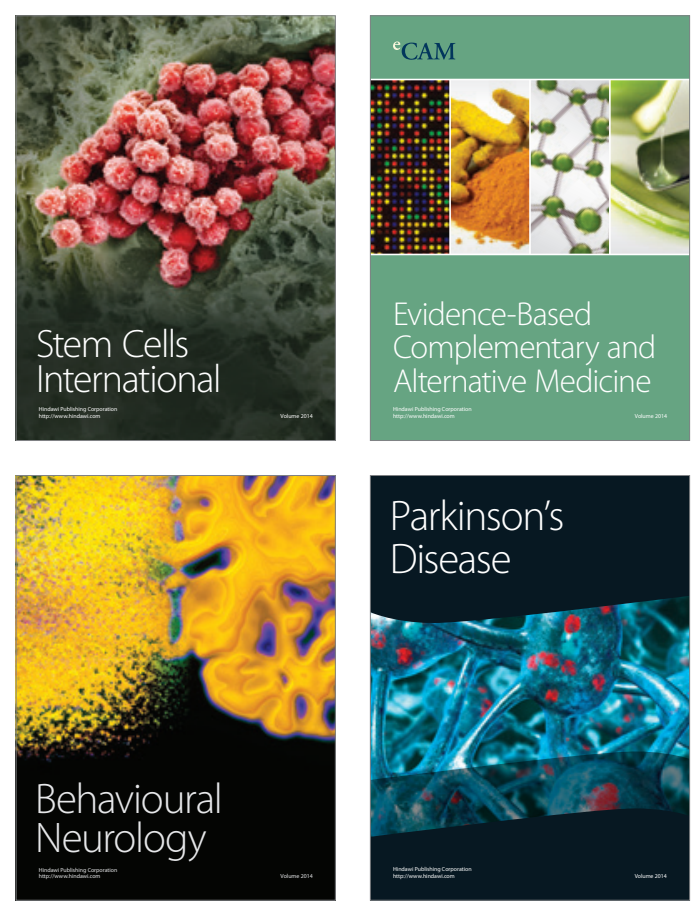

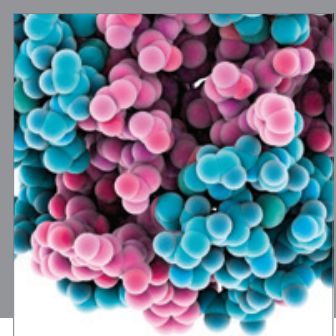

Journal of
Diabetes Research

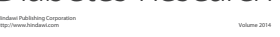

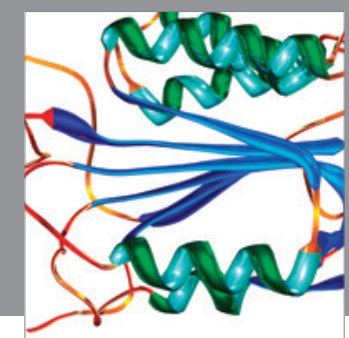

Disease Markers
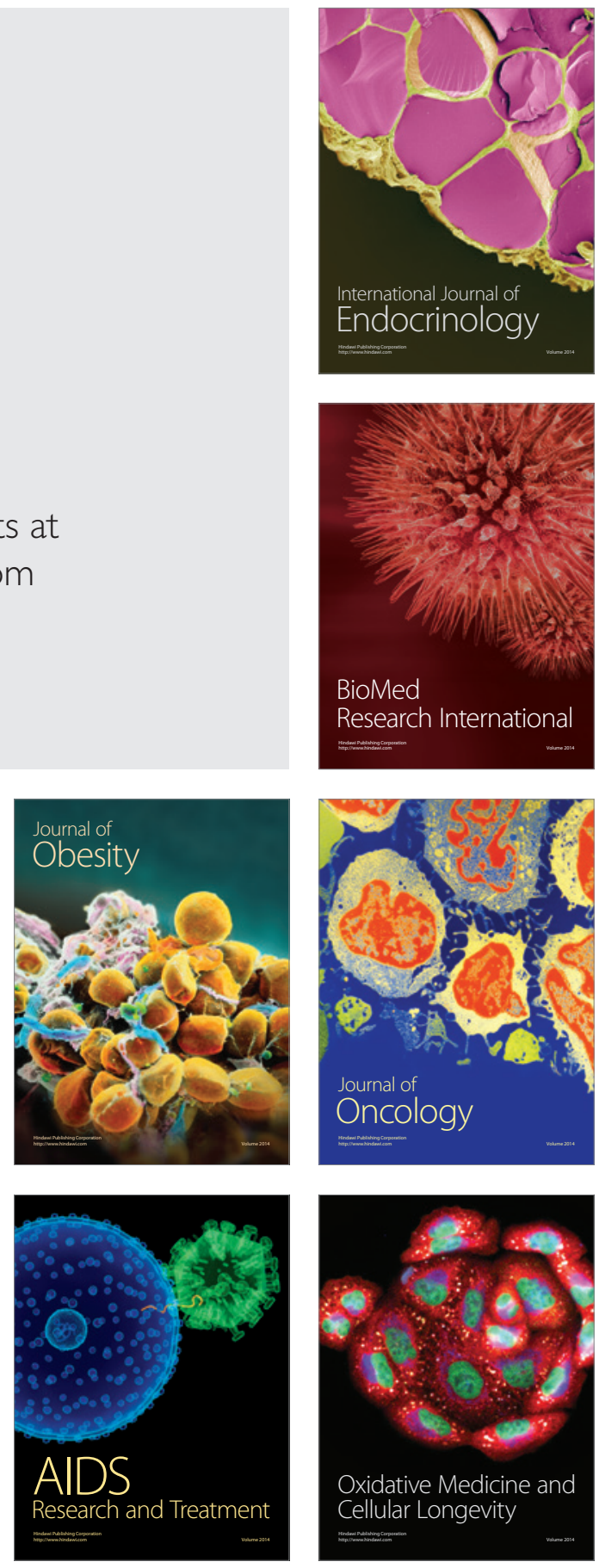